\title{
9
}

\section{Mate retention, semen displacement, and sperm competition in humans}

\author{
AARON T. GOETZ AND TODD K. SHACKELFORD \\ Florida Atlantic University
}

\section{Introduction}

Competition between males to fertilize a female's eggs can occur before, during, and after copulation (Parker, 1970; and see Birkhead \& Møller, 1998). When the sperm of two or more males simultaneously occupies the reproductive tract of a female and competes to fertilize her eggs, sperm competition occurs (Parker, 1970). Sperm competition has been documented or inferred to exist in many species, ranging from molluscs (Baur, 1998) and insects (Simmons, 2001) to birds (Birkhead \& Møller, 1992) and humans (Baker \& Bellis, 1993a, 1993b; Gallup et al., 2003; Shackelford, 2003; Shackelford et al., 2002, 2004; Smith, 1984; Wyckoff, Wang, \& Wu, 2000).

For species that practice social monogamy, the mating system in which males and females form long-term pair bonds but also pursue extra-pair copulations (e.g. most birds and humans), female sexual infidelity creates the primary context for sperm competition (Birkhead \& Møller, 1992; Smith, 1984). Males of such species may have adaptations that decrease the likelihood that a rival male's sperm will fertilize his partner's eggs - adaptations that decrease the likelihood of being cuckolded, unwittingly investing resources in genetically unrelated offspring. Male sexual jealousy, for example, is one of the most widely researched human anti-cuckoldry adaptations. Male sexual jealousy is hypothesized to motivate men to deter a mate from a sexual infidelity or a permanent defection from the mateship, and to deter rivals from mate poaching (e.g. Buss et al., 1992; Daly, Wilson, \& Weghorst, 1982; Harris, 2003; Symons, 1979; White \& Mullen, 1989). Others have described more specific adaptations that may combat sperm competition. Baker and Bellis (1993a), for example, demonstrated that men may have physiological adaptations that function to increase

(C) Cambridge University Press 2006 
the likelihood that their sperm will out-compete rival sperm to fertilize their partner's eggs. In a study of couples in committed, sexual relationships, Baker and Bellis (1993a) documented that, at the couple's next copulation, men inseminated more sperm when the couple had spent a lesser proportion of their time together since their last copulation. As the proportion of time together decreases, the likelihood of female infidelity increases, creating a higher risk of sperm competition (Baker \& Bellis, 1993a, 1995). Inseminating more sperm following a separation may function to outnumber or "flush out" rival sperm that may be present in the reproductive tract of the female (Baker \& Bellis, 1993a; Parker, 1970).

This temporally variable risk of sperm competition produces specific physiological responses apparently designed to "correct" any female sexual infidelity that might have occurred while the couple was separated. Some men, however, may be mated to women who recurrently place them at a high risk of sperm competition. Female physical attractiveness and certain personality characteristics that attract rival men, for example, may increase the likelihood of female sexual infidelity and therefore place her partner at a high recurrent risk of sperm competition. Because a woman's physical attractiveness indexes her reproductive value and fertility (Singh, 1993; Symons, 1979), physically attractive women are desired partners for long-term, short-term, and extra-pair mateships (Buss, 1989; Buss \& Schmitt, 1993; Li et al., 2002; Regan et al., 2000). Accordingly, physically attractive women are more likely to have had men try to poach them away from their current partners (Schmitt \& Buss, 2001), and men married to more physically attractive women devote more effort to retaining their mates (Buss \& Shackelford, 1997).

Direct evidence that physically attractive women are more likely to commit infidelity comes from research examining women's waist-to-hip ratios (WHRs) and their sexual behavior. WHR is a key component of female physical attractiveness (Dijkstra \& Buunk, 2001; Singh, 1993; Streeter \& McBurney, 2003). Low WHR is judged cross-culturally to be physically attractive, perhaps because it is a reliable indicator of reproductive age, sex hormone profile, and disease resistance - features associated with health and fertility (Singh, 1993). Hughes and Gallup (2003) documented that women with low WHR reported committing more infidelities and having more sexual partners than women with high WHR. Thus, because physically attractive women attract more mate poachers and commit more infidelities, they may put their partners at a high recurrent risk of sperm competition.

Another set of factors that may place a man at a high recurrent risk of sperm competition is his partner's personality traits. The five-factor model of personality describes five dimensions of stable individual differences in personality 
(Surgency, Agreeableness, Conscientiousness, Emotional Stability, and Openness to Experience; Goldberg, 1982; Norman, 1963). Schmitt and Buss (2001) found positive and significant relationships between a woman's Surgency and Openness to Experience and the likelihood of having had someone try to poach her away from an existing mateship. Similarly, Gangestad and Simpson (1990) found that women who are more socially dominant and extraverted (high in Surgency) are significantly more willing to have sex without indicators of commitment and emotional closeness. Sexual promiscuity, in turn, is a good predictor of infidelity (Hughes \& Gallup, 2003). Women who are higher in Surgency and Openness to Experience, therefore, are more often given the opportunity to engage in extra-pair copulations. No data exist on the relationship between Surgency and Openness to Experience and the actual occurrence of infidelity, but because infidelity can only occur if the opportunity for infidelity exists, a greater opportunity for infidelity translates, on average, to a greater probability of infidelity. Although not all infidelity generates sperm competition, the occurrence of sperm competition depends, in large part, on female infidelity (Baker \& Bellis, 1995; Smith, 1984).

In summary, men mated to women who are physically attractive, high in Surgency, and high in Openness to Experience may face a high recurrent risk of sperm competition. Ancestral men mated to such women would have reaped reproductive benefits if they were able to prevent or correct their partner's sexual infidelity.

\section{MATE-RETENTION TACTICS}

One solution to the adaptive problem of sperm competition is for men to prevent a partner from being sexually unfaithful (Buss, 1988; Buss \& Shackelford, 1997; Flinn, 1988; Shackelford, 2003). Buss (1988) identified 19 tactics that people use to guard or to retain their mates, ranging from vigilance over a partner's whereabouts to violence against rivals. Men and women, for example, give to their partners ornaments such as promise, engagement, or wedding rings that signal to others involvement in a romantic relationship. Also, men and women, but particularly men, attempt to prevent partner infidelity by concealing their partner (e.g. refusing to introduce a partner to same-sex friends). Because only women of reproductive age are able to cuckold their partners, Buss and Shackelford (1997) predicted and documented that male mate-retention tactics are more frequent and more intense with partners of high reproductive value, as indicated by the woman's youth and physical attractiveness. Gangestad, Thornhill, and Garver (2002) demonstrated that men increase the frequency and intensity of their mate-retention efforts during the follicular (high-conception-risk) phase of their partner's menstrual cycle. 
Because men adjust their mate-retention efforts according to their partner's reproductive value and fertility, perhaps male mate-retention tactics also are sensitive to the recurrent risk of sperm competition. This leads to the first hypothesis, tested in a recent study by Goetz et al. (2005):

Hypothesis 1: Recurrent risk of sperm competition will be related positively to the use of mate-retention tactics by men.

\section{SEMEN-DISPLACING BEHAVIORS}

Because tactics to prevent a female partner's infidelity are sometimes unsuccessful, male psychology may include mechanisms designed to "correct" a female partner's infidelity (Shackelford, 2003). Inspired by Baker and Bellis's (1993a) demonstration of male physiological adaptations to sperm competition, Shackelford et al. (2002) documented that human male psychology may include psychological adaptations to decrease the likelihood that a rival male's sperm will fertilize a female partner's eggs. For example, men who spent a greater (relative to men who spent a lesser) proportion of time apart from their partner since the couple's last copulation rated their partners as more attractive and reported greater interest in copulating with their partners. As the proportion of time spent apart increases, so too does the likelihood of female infidelity (Baker \& Bellis, 1995). Perceiving his partner as more attractive and having an increased interest in copulating with his partner may motivate a man to copulate with his partner as soon as possible, placing his sperm in competition with any rival sperm that may be present in his partner's reproductive tract.

Sperm competition also may have fashioned a psychology that generated specific corrective behaviors designed to increase the likelihood that a man's ejaculate would out-compete rival sperm. This could have been achieved by removing rival semen that was present in his partner's reproductive tract. There is both theory (Baker \& Bellis, 1995; Smith, 1984) and empirical evidence (Gallup et al., 2003) suggesting that the human penis may have evolved as a semen-displacement device. Using artificial genitals and simulated semen, Gallup et al. (2003) empirically tested the hypothesis that the human penis is designed to displace semen deposited by other men in the reproductive tract of a woman. The results indicated that artificial phalluses with glans and coronal ridge that approximated a real human penis displaced significantly more simulated semen (91\%) than did a phallus that did not have a glans and coronal ridge (35\%). When the penis is inserted into the vagina, the frenulum of the coronal ridge makes possible semen displacement by allowing semen to flow back under the penis alongside the frenulum and collect on the anterior of the 
shaft behind the coronal ridge (Gallup et al., 2003). Displacement of simulated semen only occurred, however, when a phallus was inserted at least $75 \%$ of its length (which approximates the length of the average human penis) into the artificial vagina.

That the penis must reach an adequate depth before semen is displaced suggests that successfully displacing rival semen requires specific copulatory behaviors. Following allegations of female infidelity or separation from their partners (contexts in which the likelihood of rival semen being present in the reproductive tract is relatively greater), both sexes report that men thrusted deeper and more quickly at the couple's next copulation (Gallup et al., 2003). In addition to thrusting deeply and quickly, other copulatory behaviors may be efficient semen-displacing behaviors. Men who thrusted for a longer time during sexual intercourse, for example, may have been able to displace more semen, thereby "correcting” a woman's recent sexual infidelity. Although in one previous study an extended duration of sexual intercourse did not reliably follow allegations of female infidelity or separation from partners (Gallup et al., 2003), duration of sexual intercourse has been predicted to be a semen-displacing behavior (Gallup \& Burch, 2004). The link between the likelihood of female infidelity and semen-displacing behaviors leads to a second hypothesis tested by Goetz et al. (2005):

Hypothesis 2: Recurrent risk of sperm competition will be related positively to semen-displacing behaviors.

\section{TACTIC COMPLEMENTARITY}

Baker and Bellis (1995) documented that, as female age increases (and reproductive value decreases), the rate of in-pair copulation decreases. High in-pair copulatory frequency has been proposed as a "corrective" measure in the context of sperm competition, because the relative abundance of sperm from the primary male would outnumber rival male sperm due to differential insemination frequency (Parker, 1984). Although the corrective mechanism of frequent in-pair copulations is different than the proposed corrective mechanism of semen-displacing behavior (i.e. outnumbering rival sperm versus displacing rival sperm), both tactics can produce the same result: decreasing the likelihood of cuckoldry. Buss and Shackelford (1997) documented that, as a woman's age increases, her partner's mate-retention effort decreases. The findings from Baker and Bellis (1995) and Buss and Shackelford (1997) suggest that men mated to reproductively valuable women use preventative and corrective tactics simultaneously to solve the adaptive problem of sperm competition. 
There is corroborative, comparative evidence that several bird species that practice a socially monogamous mating system similar to humans use mate retention and frequent in-pair copulation as complementary anti-cuckoldry tactics (see, e.g. Dickinson \& Leonard, 1996; Møller, 1987). This leads to a third hypothesis tested by Goetz et al. (2005):

Hypothesis 3: Male mate-retention tactics and semen-displacing behaviors are complementary tactics designed to solve the adaptive problem of sperm competition. The use of mate-retention tactics therefore will be related positively to semen-displacing behaviors.

In the remainder of this chapter, we highlight the conduct and results of Goetz et al. (2005).

\section{Methods}

\section{PARTICIPANTS}

Three hundred and five men in a committed, sexual relationship with a woman participated in the study. Participants were drawn from universities and surrounding communities. The mean age of the participants was 25.8 years ( $\mathrm{SD}=8.6$ years), and the mean age of the participants' partners was 24.6 years ( $\mathrm{SD}=8.1$ years). Goetz et al. (in press) included in the analyses data provided by men who were currently in a relationship that had lasted at least 1 year. This minimum criterion ensures that all participants were involved in a committed, long-term relationship. The mean length of the relationship in which they were involved currently was 52.6 months $(\mathrm{SD}=67.9$ months).

\section{MATERIALS}

Participants completed a survey that included several sections. The first section requested demographic information, such as the participant's age and his partner's age. The second section asked four questions to assess partner attractiveness: How physically attractive do you think your partner is?, How physically attractive do other men think she is?, How sexually attractive do you think she is?, and How sexually attractive do other men think she is? We recorded responses using a Likert-type scale ranging from 0 (Not at all) to 9 (Extremely). The third section asked the participant about his copulatory behaviors with his current partner, compared to his typical copulatory behaviors in the past. To standardize the time frame of reports, Goetz et al. (2005) asked the participant about the most recent sexual encounter with his current partner. 
The researchers assessed several copulatory behaviors, including number of thrusts, deepest thrust, depth of thrusts on average, and duration of sexual intercourse. They recorded responses using a Likert-type scale ranging from 0 (Lesser/Shorter/Fewer) to 9 (Greater/Longer/More). The fourth section asked how often the participant performed 104 mate-retention acts (from Buss, 1988) in the last month, ranging from 0 (Never) to 3 (Often). Example mate-retention acts include, "Refused to introduce my partner to same-sex friends," "Read my partner's personal mail," and "Bought my partner a small gift." The final section requested a participant's assessments of his partner's standings on the major dimensions of personality. This personality inventory included 40 bipolar items designed to assess standings on five major dimensions of personality (Botwin, Buss, \& Shackelford, 1997; example item anchors are in parentheses): Surgency (dominant - submissive), Agreeableness (flexible - stubborn), Conscientiousness (careless - careful), Emotional Stability (secure - insecure), and Openness to Experience (uncultured - cultured). For each item, participants circled a number between 1 and 7 inclusive that described their partner "generally." This measure provides reliable and valid assessments of the five major dimensions of personality and, in addition, previous work indicates substantial agreement between ratings about a target person provided by (1) that target person and (2) the target person's long-term romantic partner (see Botwin et al., 1997).

\section{PROCEDURE}

Three criteria must have been met to qualify for participation: the prospective participant must be (1) male, (2) at least 18 years of age, and (3) currently involved in a committed, romantic, sexual relationship with a woman. Prospective participants were aware of these participation criteria prior to appearing at a scheduled time and location. Upon the prospective participant's arrival at the schedule time and location, the research assistant confirmed that the prospective participant met the three participation criteria.

If the participation criteria were met, the research assistant handed the participant a consent form, the survey, and a security envelope. The participant was instructed not to seal the consent form inside the envelope to maintain anonymity. The research assistant explained to the participant the purpose of the study, answered any questions, and thanked the participant for his participation.

\section{Results}

Goetz et al. (2005) created several composite variables prior to analyses. Partner's attractiveness $(\alpha=0.86)$ is the mean of four variables: participants' rating of partner's (1) physical attractiveness and (2) sexual attractiveness, 
Table 9.1. Correlations between mate-retention tactics and recurrent risk of sperm competition, and between mate-retention tactics and semen-displacing behaviors.

\begin{tabular}{|c|c|c|}
\hline Mate retention tactic $(\alpha)$ [number of acts] & $\begin{array}{l}\text { Recurrent risk of } \\
\text { sperm competition }\end{array}$ & $\begin{array}{l}\text { Semen-displacing } \\
\text { behaviors }\end{array}$ \\
\hline Vigilance $(0.82)$ [9 acts] & 0.06 & 0.09 \\
\hline Concealment of mate $(0.65)$ [ 4 acts] & $-0.13^{*}$ & 0.07 \\
\hline Monopolization of mate $(0.75)$ [5 acts] & -0.03 & 0.04 \\
\hline Jealousy inducement (0.72) [4 acts] & -0.09 & 0.01 \\
\hline Punishment of threat to infidelity (0.82) [7 acts] & -0.01 & 0.09 \\
\hline Emotional manipulation $(0.81)$ [8 acts] & -0.03 & 0.05 \\
\hline Commitment manipulation $(0.50)[3 \mathrm{acts}]$ & $0.13^{*}$ & $0.24^{\ddagger}$ \\
\hline Derogation of competitors (0.77) [7 acts] & -0.08 & 0.01 \\
\hline Resource display $(0.86)[6 \mathrm{acts}]$ & $0.28^{\ddagger}$ & $0.24^{\ddagger}$ \\
\hline Sexual inducement $(0.62)[5$ acts $]$ & $0.14^{*}$ & $0.16^{\dagger}$ \\
\hline Appearance enhancement (0.77) [5 acts] & $0.22^{\ddagger}$ & $0.13^{*}$ \\
\hline Love and care $(0.67)[5$ acts $]$ & $0.31^{\ddagger}$ & $0.17^{\ddagger}$ \\
\hline Submission and debasement (0.68) [5 acts] & 0.05 & 0.09 \\
\hline Verbal possession signals $(0.65)[5$ acts $]$ & $0.20^{\ddagger}$ & $0.18^{\dagger}$ \\
\hline Physical possession signals $(0.72)$ [ $5 \mathrm{acts}]$ & $0.27^{\ddagger}$ & $0.13^{*}$ \\
\hline Possessive ornamentation $(0.66)[5$ acts $]$ & $0.16^{\dagger}$ & $0.16^{\dagger}$ \\
\hline Derogation of mate $(0.70)[5$ acts $]$ & $-0.24^{\ddagger}$ & 0.01 \\
\hline Intrasexual threats $(0.84)$ [6 acts] & 0.05 & $0.12^{*}$ \\
\hline Violence against rivals $(0.82)$ [5 acts] & -0.05 & 0.11 \\
\hline
\end{tabular}

Note: From Goetz et al. (2005); $n=305 . \alpha=\alpha$ reliability.

${ }^{*} P<0.05 ;{ }^{\dagger} P<0.01 ;{ }^{\ddagger} P<0.001$ (two-tailed).

and participants' rating of other men's assessments of partner's (3) physical attractiveness and (4) sexual attractiveness. Semen-displacing behavior $(\alpha=0.81)$ is the mean of four variables: (1) number of thrusts, (2) deepest thrust, (3) depth of thrusts on average, and (4) duration of sexual intercourse.

Goetz et al. (2005) calculated scores for 19 mate-retention tactics using responses to the 104 mate-retention acts, following Buss (1988; and see Buss \& Shackelford, 1997). The researchers calculated scores for participants' partners on the five major dimensions of personality using responses to the Botwin et al. (1997) 40-item instrument. $\alpha$ Reliabilities for the 19 mate-retention tactics varied in this study from $\alpha=0.50$ to 0.86 (see Table 9.1). For use in several statistical analyses, the researchers created a composite mate-retention variable $(\alpha=0.97)$ by averaging responses on the 19 mate-retention tactics. $\alpha$ Reliabilities for the target partner personality dimensions were: Surgency, $\alpha=0.62$ and Openness to Experience, $\alpha=0.63$. The researchers created a composite recurrent risk of 
sperm competition variable $(\alpha=0.66)$ by averaging scores on partner's attractiveness, partner's Surgency, and partner's Openness to Experience. The researchers scaled partner's attractiveness differently from the personality measures, so they standardized the three variables prior to averaging.

Hypothesis 1 stated that recurrent risk of sperm competition will be related positively to the use of mate-retention tactics by men. Consistent with this hypothesis, recurrent risk of sperm competition correlated positively with the use of mate-retention tactics; $r(303)=0.14(P<0.05)$. Men mated to women who place them at a higher recurrent risk of sperm competition reported more frequent use of mate-retention tactics. Although the focus of Hypothesis 1 was the relationship between recurrent risk of sperm competition and the broad use of mate-retention tactics, Goetz et al. (2005) also investigated the relationship between recurrent risk of sperm competition and use of each of the 19 materetention tactics (see Table 9.1) reported by Buss (1988) and Buss and Shackelford (1997). Eight of the 19 tactics showed significant positive correlations with recurrent risk of sperm competition (commitment manipulation, resource display, sexual inducement, appearance enhancement, love and care, verbal possession signals, physical possession signals, and possessive ornamentation), and two of the 19 tactics showed significant negative correlations with recurrent risk of sperm competition (concealment of mate and derogation of mate).

Hypothesis 2 stated that recurrent risk of sperm competition will be related positively to semen-displacing behaviors. Consistent with this hypothesis, recurrent risk of sperm competition correlated positively with semendisplacing behaviors; $r(303)=0.33(P<0.001)$. Men mated to women who place them at a higher recurrent risk of sperm competition reported performing more copulatory behaviors arguably designed to displace rival semen. For reportorial completeness, Goetz et al. (2005) also investigated the relationship between recurrent risk of sperm competition and use of each of the four individual semen-displacing behaviors (see Table 9.2). All four correlations were significant and positive, ranging from $r(303)=0.21$ to 0.32 (all $P$ values $<0.001$ ).

Hypothesis 3 stated that the use of mate-retention tactics will be related positively to semen-displacing behaviors. Consistent with this hypothesis, the use of mate-retention tactics correlated positively with semen-displacing behaviors; $r(303)=0.19(P<0.01)$. This positive correlation suggests that men used mate-retention tactics and semen-displacing behaviors simultaneously. Goetz et al. (2005) also investigated the relationship between semen-displacing behaviors and each of the 19 mate-retention tactics reported by Buss (1988) and Buss and Shackelford (1997; see Table 9.1). Nine of the 19 tactics were positively and significantly correlated with semen-displacing behaviors (commitment manipulation, resource display, sexual inducement, appearance enhancement, 
Table 9.2. Correlations between semen-displacing behaviors and recurrent risk of sperm competition.

\begin{tabular}{ll}
\hline \hline Semen-displacing behaviors & $\begin{array}{l}\text { Recurrent risk of sperm } \\
\text { competition }\end{array}$ \\
\hline Number of thrusts & $0.22^{\ddagger}$ \\
Deepest thrust & $0.32^{\ddagger}$ \\
Depth of thrusts, on average & $0.31^{\ddagger}$ \\
Duration of sexual & $0.21^{\ddagger}$ \\
$\quad$ intercourse & \\
\hline \hline
\end{tabular}

Note: From Goetz et al. (2005); $n=305$. Each semen-displacing behavior is a relative measure; the participant compared his copulatory behaviors with his current partner to his typical copulatory behaviors in the past. ${ }^{\ddagger} \mathrm{P}<0.001$ (two-tailed).

love and care, verbal possession signals, physical possession signals, possessive ornamentation, and intrasexual threats).

\section{Discussion}

Shackelford (2003) proposed three separate adaptive problems associated with sperm competition in human males: preventing a female partner's sexual infidelity, correcting a female partner's sexual infidelity, and anticipating a female partner's sexual infidelity. The research by Goetz et al. (2005) represents a preliminary investigation of how men might solve the adaptive problems of preventing and correcting a partner's infidelity. More specifically, this study tested the hypotheses that men mated to women that recurrently place them at a high risk of sperm competition may solve this adaptive problem through preventative and corrective measures, and that the preventative and corrective measures are complementary, working together to solve the adaptive problem of sperm competition. Behaviors that functioned to prevent and correct a female partner's sexual infidelity may have been selected for in a socially monogamous species such as humans (Baker \& Bellis, 1995; Shackelford, 2003; Smith, 1984). The results suggest that men perform both preventative and corrective behaviors when under a high recurrent risk of sperm competition.

Women who are physically attractive and have personality characteristics that attract rival men are more often given the opportunity to be sexually unfaithful and may be more likely to commit sexual infidelity, thereby placing their partners at a higher recurrent risk of sperm competition. The female partner's physical attractiveness, Surgency, and Openness to Experience index 
a man's recurrent risk of sperm competition. Men mated to such women may solve the adaptive problem of sperm competition through preventative and corrective measures. Goetz et al. (2005) operationalized preventative measures as the use of mate-retention tactics (Buss, 1988), and we operationalized corrective measures as male copulatory behaviors consisting of relatively deep, numerous thrusts for a prolonged period of time - behaviors that may be effective at displacing rival semen present in the reproductive tract of a woman (Gallup et al., 2003).

The results supported all three hypotheses. Men mated to women who have traits linked to a higher probability of sexual infidelity more frequently use mate-retention tactics apparently designed to thwart potential infidelity. Men mated to women who have traits linked to a higher probability of sexual infidelity also are more likely to perform copulatory behaviors arguably designed to displace rival male semen present in the woman's reproductive tract. Finally, the results indicate that male mate-retention tactics and semen-displacing behaviors are complementary tactics used simultaneously to reduce sperm-competition risk and the consequences of sperm competition (e.g. cuckoldry).

The majority of copulations in humans are in-pair copulations (Baker \& Bellis, 1995) and, therefore, semen-displacing behaviors performed by the primary male usually will displace his own semen. The consequences of such an effect might be minimized, however, if the temporal spacing between successive in-pair copulations is greater than the spacing between copulations involving different men. The refractory period may have been designed for this purpose (Gallup \& Burch, 2004). Moreover, Gallup and Burch (2004) have suggested that penile hypersensitivity and loss of an erection (two events that follow ejaculation) may function to reduce the occurrence of self-semen displacement.

Although the sooner a man performs semen-displacing behaviors the more likely he is to displace recently deposited rival semen, it is not clear, at present, how long the "corrective window" may be. Because the human penis cannot enter the cervix to displace semen, the corrective window should be proportional to the time that sperm remain in the vagina. Although some sperm have been found in the cervix and oviducts within minutes of coitus, they are often dead (Johnson \& Everitt, 1995; Porter \& Flinn, 1977). Evidence from reproductive biology suggests that human sperm can be stored for varying time periods within the vaginal cavity (see, e.g. Baker \& Bellis, 1995; Johnson \& Everitt, 1995; Morris, 1977; Smith, 1984). One way to determine the length of the corrective window is to establish the proportion of time that sperm remain in the vagina. Another way to determine the length of the corrective window may be to correlate semen-displacing behaviors as a function of time since last sexual 
intercourse. The length of the corrective window will be revealed as semendisplacing behaviors begin to decrease as the time since last sexual intercourse increases.

Most of the relationships assessed by Goetz et al. (2005) between recurrent risk of sperm competition and mate-retention tactics are positive, indicating that men mated to women who place them at high recurrent risk of sperm competition more frequently perform mate-retention behaviors. Recurrent risk of sperm competition correlates positively with the mate-retention tactic sexual inducement, for example. Sexual inducement includes the following items: "He gave in to her sexual requests," "He performed sexual favors to keep his partner around," "He had a physical relationship with her to deepen their bond," and "He gave in to sexual pressure to keep her." Although the phrasing of these items suggests that sexual inducement is used more often by women, Buss (1988) found a sex difference in the opposite direction (i.e. men reported using sexual inducement more than women). From the perspective of spermcompetition theory (Parker, 1970), the sexual inducement tactic can be interpreted as a "corrective" tactic designed to place a man's sperm in competition with any rival sperm that may be present in his partner's reproductive tract.

Limiting factors such as time, energy, and resources do not allow men to perform every mate-retention tactic all the time, and some tactics may be avoided deliberately. Many of the non-significant correlations between recurrent risk of sperm competition and the mate-retention tactics involve "negative" tactics (i.e. tactics likely to be perceived negatively by one's partner), such as vigilance, monopolization of time, and emotional manipulation. Performing negative mate-retention tactics is likely to excite conflict in a relationship. Goetz et al. (2005) speculated that, to avoid such conflict, men mated to women who are more likely to commit sexual infidelity do not attempt to retain their mates using these negative tactics.

Indeed, recurrent risk of sperm competition correlated negatively and significantly with the mate-retention tactics derogation of mate and concealment of mate. Derogation of mate includes items such as, "He told other guys she was not a nice person," "He told other guys she was stupid," and "He told others she was a pain." Perhaps men mated to women who are more likely to commit sexual infidelity do not attempt to retain their mates by derogating their mates to competitors because this derogation may signal to competitors impending relationship dissolution, prompting competitors to pursue the woman. Directing rival men to a mate who is likely to commit sexual infidelity is unlikely to have been a reproductively profitable strategy.

Examining the relationship between recurrent risk of sperm competition and each of the four semen-displacing behaviors reveals that men mated to 
women who place them at high recurrent risk of sperm competition report that during sexual intercourse with their partner (1) they thrust more frequently, (2) their deepest thrust is more deep, (3) the depth of their thrusts is much deeper on average, and (4) the duration of sexual intercourse is much longer. That men report that their deepest thrust is more deep than usual and that the depth of their thrusts is much deeper on average corroborates Gallup et al.'s (2003) demonstration that the penis must reach an adequate depth to displace semen successfully. The other copulatory behaviors - number of thrusts and duration of sexual intercourse - also may contribute to semen displacement. Thrusting more frequently during intercourse and a longer duration of intercourse may afford a man greater opportunity to displace rival semen. Although not found in Gallup et al.'s (2003) work, duration of sexual intercourse was predicted to be a semen-displacing behavior by Gallup and Burch (2004).

All of the relationships assessed by Goetz et al. (2005) between semen-displacing behaviors and mate-retention tactics are positive and several achieve statistical significance, suggesting that the two sets of behaviors are used simultaneously to solve the adaptive problem of sperm competition. This concurs with crossspecies evidence that several bird species use preventative and corrective tactics as complementary anti-cuckoldry tactics (see, e.g. Dickinson \& Leonard, 1996; Møller, 1987).

Semen-displacing behaviors correlate positively with the mate-retention tactic sexual inducement, for example. When men are giving in to their partners' sexual requests, performing sexual favors to keep their partners around, having a physical relationship with their partners to deepen their bond, and giving in to sexual pressure to keep their partner, they are performing semen-displacing behaviors during these acts. This relationship supports the interpretation of sexual inducement as a corrective tactic designed to (a) place a man's sperm in competition with any rival sperm that may be present in his partner's reproductive tract, or (b) displace semen deposited by rival males.

An alternative explanation for the occurrence of semen-displacing behaviors in men who are mated to women who place them at a high recurrent risk of sperm competition might be that such men thrust more deeply and frequently, for example during sexual intercourse, because they are extremely sexually aroused as a result of their partners' physical attractiveness (a key component of high recurrent risk of sperm competition). Proponents of the "heightened sexual arousal" hypothesis must answer why men are more sexually aroused by physically attractive partners, however. Shackelford et al. (2002) argued that perceiving his partner as more attractive and becoming more sexually aroused may motivate a man to copulate with his partner as soon as possible, placing his 
sperm in competition with any rival sperm that may be present in his partner's reproductive tract. So the heightened sexual arousal hypothesis is not an alternate hypothesis.

Another alternative explanation for the occurrence of semen-displacing behaviors in men who are mated to women who place them at a high recurrent risk of sperm competition might be that women who are attractive, sexy, dominant, sociable, curious, creative, and knowledgeable are simply more open to intense, varied, and prolonged copulatory behavior with their partners. To address this possibility, Goetz et al. (2005) assessed the woman's sexual openness by asking the participant, "In general, how open is your partner about sexual matters?" Goetz et al. identified no significant correlations between sexual openness and physical attractiveness, Surgency, and Openness to Experience. Thus, attractive, sexy, dominant, sociable, curious, creative, knowledgeable women are not simply more open to their partners' intense, varied, and prolonged copulatory behaviors.

\section{LIMITATIONS AND FUTURE RESEARCH DIRECTIONS}

This research by Goetz et al. (2005) has several limitations. One limitation of the study is in its design. Goetz et al. present correlational analyses that prevent strong statements about causal relationships. Goetz et al. speculate that mateship to women who have traits linked to a higher probability of sexual infidelity causes men to perform mate-retention tactics and semen-displacing behaviors. The data are consistent with this interpretation, but we cannot yet rule out an alternative, reverse causal relationship - that performing preventative and corrective measures causes men to select as mates women who have traits linked to a higher probability of sexual infidelity. A methodology that includes repeated assessments of the key variables over time, such as a daily diary study, would allow for the identification of causal relationships.

An arguable design limitation of this research is the use of men's reports of their female partners' attractiveness and personality standings. Perhaps the results would have turned out differently if Goetz et al. (2005) had collected independent ratings on these key variables. This is not likely, however, because previous research indicates that men's ratings of their female partners' attractiveness and personality standings correlate positively with independent ratings (and with women's self-reports) on these variables (see, e.g. Botwin et al., 1997; Buss \& Shackelford, 1997). Furthermore, it is the male's perception of his partner's physical attractiveness and personality that are important. The male's perception provides the input that is transformed through psychological processes (i.e. decision rules) into behavioral output (e.g. perform semen-displacing behaviors or do not perform semen-displacing behaviors). 
There may be concern about the validity of the self-reported assessments of specific copulatory behaviors. The validity of this self-report methodology has been established in several different ways. Masters and Johnson (1966) provided some of the first evidence for the substantial agreement between self-reports of specific copulatory behaviors and these same behaviors as observed directly and recorded by the researchers. In several dozen studies with several hundred participants, Masters and Johnson (1966) documented that people can accurately report the occurrence of specific copulatory behaviors. For the majority of specific copulatory behaviors, recollected reports of these behaviors are in substantial agreement with the actual behaviors observed or recorded by the researchers. As is true for most recollections, this agreement between selfreports and actual behavior is greater the closer in time the recollections are to the actual behaviors. This agreement is substantial, however, even after a period of several weeks or months (see research reviewed in Allgeier \& Allgeier, 2000; Crooks \& Baur, 2002; Hyde \& DeLamater, 2003; and Masters, Johnson, \& Kolodny, 1997). Goetz et al. (2005) assessed self-reported copulatory behaviors that occurred at the most recent sexual encounter with the participant's regular partner. In this relatively young sample, it is typical that most individuals have sexual intercourse with their partners two to three times per week (see Baker \& Bellis, 1995; Smith, 1984). Hence, the last sexual encounter is not likely to have occurred more than 2 or 3 days prior to the survey administration. This is not a long period over which to provide recollections and, therefore, the selfreported assessments of specific copulatory behaviors should not prove to be problematic.

There are several additional directions for future work. Future research should examine semen-displacing behaviors following an actual female sexual infidelity. Goetz et al. (2005) examined the relationships between the likelihood of female sexual infidelity (as assessed by her physical attractiveness and personality traits) and male mate-retention and semen-displacing behaviors. More intense mate-retention and semen-displacing behaviors may be detectable under conditions of suspected or confirmed sexual infidelity.

Future research also might attempt to establish the woman's role when men employ these preventative and corrective measures, particularly because the interests of men and women often are in conflict. If she is seeking genetic benefits in her extra-pair copulations (Cashdan, 1996; Gangestad \& Simpson, 2000; Scheib, 2001), for example, a woman who was inseminated recently by an extra-pair partner may resist or find unpleasant her regular partner's "corrective" semen-displacing behaviors. In addition, we might hypothesize that she might counter her partners' semen-displacing behaviors by failing to achieve a sperm-retaining orgasm with her regular partner (Baker \& Bellis, 1993b, 1995). 
In conclusion, a wide variety of human male psychological adaptations may have been designed by selection due to sperm competition. To prevent sperm competition, men perform mate-retention tactics apparently designed to reduce the likelihood of female sexual infidelity. Because preventative tactics are not fail-safe, however, men perform specific copulatory behaviors apparently designed to correct female sexual infidelity by displacing rival semen that may be present in the woman's reproductive tract. These tactics may accompany physiological adaptations (Baker \& Bellis, 1993a) and other psychological adaptations (Shackelford et al., 2002) to solve the adaptive problem of human sperm competition.

\section{References}

Allgeier, E. R. and Allgeier, A. R. (2000). Sexual Interactions, 5th edn. Boston: Houghton Mifflin.

Baker, R. R. and Bellis, M. A. (1993a). Human sperm competition: ejaculate adjustment by males and the function of masturbation. Animal Behaviour, 46, 861-85.

Baker, R. R. and Bellis, M. A. (1993b). Human sperm competition: ejaculate manipulation by females and a function for the female orgasm. Animal Behaviour, 46, 887-909.

Baker, R. R. and Bellis, M.A. (1995). Human Sperm Competition. London: Chapman \& Hall.

Baur, B. (1998). Sperm competition in molluscs. In T. R. Birkhead and A. P. Møller, eds., Sperm Competition and Sexual Selection. San Diego: Academic Press, pp. 255-305.

Birkhead, T. R. and Møller, A. P. (1992). Sperm Competition in Birds. London: Academic Press.

Birkhead, T. R. and Møller, A. P. (eds.). (1998). Sperm Competition and Sexual Selection. San Diego: Academic Press.

Botwin, M. D., Buss, D. M., and Shackelford, T. K. (1997). Personality and mate preferences: five factors in mate selection and marital satisfaction. Journal of Personality, 65, 107-36.

Buss, D. M. (1988). From vigilance to violence: tactics of mate retention in American undergraduates. Ethology and Sociobiology, 9, 291-317.

Buss, D. M. (1989). Sex differences in human mate preferences: evolutionary hypotheses tested in 37 cultures. Behavioral and Brain Sciences, 12, 1-49.

Buss, D. M. and Schmitt, D. (1993). Sexual strategies theory: an evolutionary perspective on human mating. Psychological Review, 100, 204-32.

Buss, D. M. and Shackelford, T. K. (1997). From vigilance to violence: mate retention tactics in married couples. Journal of Personality and Social Psychology, 72, 346-61.

Buss, D. M., Larsen, R. J., Westen, D., and Semmelroth, J. (1992). Sex differences in jealousy: evolution, physiology and psychology. Psychological Science, 3, 251-5.

Cashdan, E. (1996). Women's mating strategies. Evolutionary Anthropology, 5, 134-43.

Crooks, R. L. and Baur, K. (2002). Our sexuality (8th edn). Pacific Grove, CA: Brooks/Cole. 
Daly, M., Wilson, M., and Weghorst, J. (1982). Male sexual jealousy. Ethology and Sociobiology, 3, 11-27.

Dickinson, J. L. and Leonard, M. L. (1996). Mate attendance and copulatory behaviour in western bluebirds: evidence of mate guarding. Animal Behaviour, 52, 981-92.

Dijkstra, P. and Buunk, B. P. (2001). Sex differences in the jealousy-evoking nature of a rival's body build. Evolution and Human Behavior, 22, 335-41.

Flinn, M. V. (1988). Mate guarding in a Caribbean village. Ethology and Sociobiology, 9, 1-28.

Gallup G. G. and Burch, R. L. (2004). Semen displacement as a sperm competition strategy in humans. Evolutionary Psychology, 2, 12-23.

Gallup G. G., Burch, R. L., Zappieri, M. L., et al. (2003). The human penis as a semen displacement device. Evolution and Human Behavior, 24, 277-89.

Gangestad, S. W. and Simpson, J. A. (1990). Toward an evolutionary history of female sociosexual variation. Journal of Personality, 58, 69-96.

Gangestad, S. W. and Simpson, J. A. (2000). The evolution of human mating: trade-offs and strategic pluralism. Behavior and Brain Sciences, 23, 573-87.

Gangestad, S. W., Thornhill, R., and Garver, C. E. (2002). Changes in women's sexual interests and their partner's mate-retention tactics across the menstrual cycle: evidence for shifting conflicts of interest. Proceedings of the Royal Society of London B, 269, 975-82.

Goetz, A. T., Shackelford, T. K., Weekes-Shackelford, V.A., et al. 2005 (in press). Mate retention, semen displacement, and human sperm competition: a preliminary investigation of tactics to prevent and correct female infidelity. Personality and Individual Differences, 38, 749-63.

Goldberg, L. R. (1982). From ace to zombie: some explorations in the language of personality. In C. D. Spielberg and J. N. Butcher, eds., Advances in Personality Assessment. Hillsdale, NJ: Erlbaum, vol. 1, pp. 203-34.

Harris, C. R. (2003). A review of sex differences in sexual jealousy, including selfreport data, psychophysiological responses, interpersonal violence, and morbid jealousy. Personality and Social Psychology Review, 7, 102-28.

Hughes, S. M. and Gallup, G. G. (2003). Sex differences in morphological predictors of sexual behavior: shoulder to hip and waist to hip ratios. Evolution and Human Behavior, 24, 173-8.

Hyde, J. S. and DeLamater, J. (2003). Understanding Human Sexuality, 8th edn. Boston: McGraw-Hill.

Johnson, M. H. and Everitt, B. J. (1995). Essential Reproduction, 4th edn. Oxford: Blackwell Science.

Li, N. P., Bailey, J. M., Kenrick, D. T., and Linsenmeier, J. A. W. (2002). The necessities and luxuries of mate preferences: testing the tradeoffs. Journal of Personality and Social Psychology, 82, 947-56.

Masters, W.H. and Johnson, V.E. (1966). Human Sexual Response. Boston: Little, Brown, \& Co.

Masters, W. H., Johnson, V.E., \& Kolodny, R. C. (1997). Humans Sexuality. New York: Harper Collins. 
Møller, A. P. (1987). Mate guarding in the swallow Hirundo rustica. Behavioral Ecology 8 Sociobiology, 21, 119-23.

Morris, J. M. (1977). The morning-after pill: a report on postcoital contraception and interception. In R. O. Greep and M. A. Koblinsky, eds., Frontiers in Reproductive and Fertility Control. Cambridge, MA: MIT Press, pp. 203-8.

Norman, W.T. (1963). Toward an adequate taxonomy of personality attributes: replicated factor structure in peer nominations and personality ratings. Journal of Personality and Social Psychology, 66, 574-83.

Parker, G. A. (1970). Sperm competition and its evolutionary consequences in the insects. Biological Review, 45, 525-67.

Parker, G. A. (1984). Sperm competition and the evolution of animal mating strategies. In R. L. Smith, ed., Sperm Competition and the Evolution of Animal Mating Systems. London: Academic Press, pp. 1-60.

Porter, D. G. and Flinn, C. A. (1977). The biology of the uterus. In R. O. Greep \& M. A. Koblinsky, eds., Frontiers in Reproductive and Fertility Control. Cambridge, MA: MIT Press, pp. 146-56.

Regan, P. C., Levin, L., Sprecher, S., Christopher, F. S., and Cate, R. (2000). Partner preferences: what characteristics do men and women desire in their short-term sexual and long-term partners? Journal of Psychology \& Human Sexuality, 12, 1-21.

Scheib, J. E. (2001) Context-specific mate choice criteria: women's trade-offs in the contexts of long-term and extra-pair mateships. Personal Relationships, 8, 371-89.

Schmitt, D. P. and Buss, D. M. (2001). Human mate poaching: tactics and temptations for infiltrating existing mateships. Journal of Personality and Social Psychology,

80, 894-917.

Shackelford, T. K. (2003). Preventing, correcting, and anticipating female infidelity: three adaptive problems of sperm competition. Evolution and Cognition, 9, 90-6.

Shackelford, T. K., Goetz, A. T., LaMunyon, C. W., et al. (2004). Sex differences in sexual psychology produce sex similar preferences for a short-term mate. Archives of Sexual Behavior, 33, 405-12.

Shackelford, T. K., LeBlanc, G. J., Weekes-Shackelford, V.A., et al. (2002). Psychological adaptation to human sperm competition. Evolution and Human Behavior, 23, 123-38.

Simmons, L. W. (2001). Sperm Competition and its Evolutionary Consequences in the Insects. Princeton, NJ: Princeton University Press.

Singh, D. (1993). Adaptive significance of waist-to-hip ratio and female physical attractiveness. Journal of Personality and Social Psychology, 65, 293-307.

Smith, R. L. (1984). Human sperm competition. In R. L. Smith, ed., Sperm Competition and the Evolution of Animal Mating Systems. New York: Academic Press, pp. 601-60.

Streeter, S. A. and McBurney, D. H. (2003). Waist-hip ratio and attractiveness: new evidence and a critique of "a critical test". Evolution and Human Behavior, 24, 88-98.

Symons, D. (1979). The Evolution of Human Sexuality. New York: Oxford University Press. White, G. L. and Mullen, P.E. (1989). Jealousy. New York: Guilford Press.

Wyckoff, M., Wang, W., and Wu, C. (2000). Rapid evolution of male reproductive genes in the descent of man. Nature, 403, 304-8. 